\title{
Evaluating the Effect of Standard of Care Treatment on Burden of Chronic Hepatitis B: A Retrospective Analysis of the United States Veterans Population
}

\author{
Urbano Sbarigia · Furaha Kariburyo · Janvi Sah · Jamie Colasurdo • \\ Lin Xie · Eva G. Katz · Shirley Sylvester
}

Received: October 17, 2019 / Published online: February 2, 2020

(C) The Author(s) 2020

\begin{abstract}
Introduction: This study aimed to characterize chronic hepatitis B (CHB)-infected patients and estimate the association between nucleos(t)ide analogue (NA) persistence and economic outcomes using data from the Veterans Health Administration (VHA) database.

Methods: Patients (at least 18 years of age) with two or more claims for $\mathrm{CHB}$ and at least one pharmacy claim for NA were identified using
\end{abstract}

Enhanced Digital Features To view enhanced digital features for this article go to https://doi.org/10.6084/ m9.figshare.11322845.

Electronic supplementary material The online version of this article (https://doi.org/10.1007/s12325020-01240-1) contains supplementary material, which is available to authorized users.

\section{U. Sbarigia}

Janssen Scientific Affairs, Pharmaceutica NV, Global

Health Economics and Market Access, Beerse,

Belgium

F. Kariburyo $(\bowtie) \cdot$ J. Sah $\cdot$ L. Xie

STATinMED Research, Health Economics and

Outcomes Research, Ann Arbor, MI, USA

e-mail: fkariburyo@statinmed.com

J. Colasurdo · E. G. Katz

Janssen Research and Development, Epidemiology,

Raritan, NJ, USA

S. Sylvester

Janssen Pharmaceutica NV, Women's Health,

Titusville, NJ, USA
VHA data from 1 April 2013 to 31 March 2018. The index date was the first NA prescription fill date during 1 October 2014 to 31 March 2017. Persistence and non-persistence to NA treatment were assessed during the first 2 years post index date. Non-persistence was defined as at least one failure to refill medication within 30 days from the run-out date. Generalized linear models were used to compare health care utilization and costs between persistent and non-persistent patients.

Results: Among patients treated with NAs $(N=2368), 1428(60 \%)$ were CHB mono-infected and 748 (32\%) were HIV co-infected. Total costs per patient per year (PPPY) were $\$ 39,240, \$ 29,957$, and $\$ 55,220$ PPPY for NAtreated, mono-infected, and HIV co-infected patients, respectively. An inception cohort of 564 patients $(24 \%)$, without a NA prescription in the 6 months pre-index period and at least 2 years of follow-up, was created. Persistence among the inception cohort was $29 \%$ for first year and 14\% for first 2 years. After adjustment for baseline differences, persistent patients had lower cumulative overall health care costs compared to non-persistent patients, with a net cost saving of $\$ 851(p>0.05)$ in the first 2 years. Conclusion: $\mathrm{CHB}$ is associated with considerable economic burden. We observed suboptimal persistence to NAs which decreased over time. Short-term savings could be generated for CHBinfected patients when they remain persistent to NAs. 
Keywords: Chronic hepatitis B; Economic burden; Infectious disease; Nucleos(t)ide analogues; Persistence

\section{Key Summary Points}

Why carry out this study?

There is a lack of evidence regarding treatment persistence to nucleos(t)ide analogues (NAs) and the economic burden among persistent patients with chronic hepatitis $\mathrm{B}(\mathrm{CHB})$ versus those who are not.

This study evaluated patient characteristics and health care utilization and costs in the NAs-treated CHB-infected US veteran population, stratified by coinfection and persistence.

\section{What was learned from the study?}

Persistence among newly treated patients with $\mathrm{CHB}$ was $29 \%$ for 1 st year and $14 \%$ for first 2 years with a net cost saving of $\$ 851$ for persistent patients compared to non-persistent patients.

There is a significant short-term cost saving for CHB-infected patients when they remain persistent to their NAs during the first 2 years of follow-up.

Thus, there is an unmet medical need for effective treatments with a finite duration that can help provide sustained undetectable viral load or functional cure to achieve desired treatment benefits for patients with CHB.

\section{INTRODUCTION}

Hepatitis B virus (HBV) infection is a global public health problem affecting an estimated 292 million people worldwide [1]. In the USA, 3.1 million people are affected by chronic hepatitis B (CHB) virus infection [1], and nearly $40 \%$ of patients with $\mathrm{CHB}$ die annually as a result of complications such as cirrhosis and hepatocellular carcinoma (HCC) $[2,3]$. Despite the availability of a prophylactic vaccine, the number of people diagnosed with $\mathrm{CHB}$ continues to rise primarily because of the asymptomatic nature of the first stages of the disease [4]. Moreover, $31.6 \%$ of adults with chronic conditions have HBV vaccine coverage (at least three doses) per the Centers for Disease Control and Prevention (CDC) [5].

The American Association for the Study of Liver Disease (AASLD) and European Association for the Liver (EASL) guidelines define functional cure as the induction of sustained, undetectable hepatitis B surface antigen loss (HBsAg) and hepatitis B virus (HBV) DNA in serum with or without seroconversion to hepatitis B surface antibody (anti-HBs) after completion of a finite course of treatment [6]. Functional cure is the optimal CHB treatment endpoint; however, it is rarely achieved with current antiviral treatments [7, 8]. In fact, functional cure during long-term nucleos(t)ide analogue (NA) therapy may occur in only $1-3 \%$ of cases [9-11]. Treatment with interferon and its pegylated forms offers a slightly higher rate of functional cure (5-7\%); however, these therapies are rarely used given their suboptimal safety and tolerability profile [8].

Similarly, other current CHB treatments, such as NAs, rarely lead to functional cure (e.g., sustained HBsAg loss and undetectable HBV DNA), leading patients to require a chronic treatment duration (often lifetime) to achieve desired benefits. Consequently, life-long treatment represents a clinical and economic burden for patients with $\mathrm{CHB}$ that includes liver disease progression, negative effects on quality of life, increased medical resource utilization and poor outcomes associated with suboptimal adherence, and increased health care visits and hospitalizations [12-14]. Current guidelines underscore that optimal medication adherence to $\mathrm{CHB}$ treatment is required to attain the best (clinical) results. Non-adherence to treatment is the main driver for suboptimal treatment response among patients with $\mathrm{CHB}$ resulting in virological failure, HBV flares, and increased risk of mortality [15-17]. Currently there is a need to better understand the medication-taking behavior of patients with CHB. However, 
assessing adherence using real-world databases is challenging because there is limited information on daily dosing and medication-taking behavior. Therefore, treatment persistence, which measures the duration of a prescribed treatment, might allow for the evaluation of patients' health outcomes using real-world evidence.

Treatment persistence to NAs among patients with $\mathrm{CHB}$ is not well documented. Furthermore, there is a lack of evidence regarding the economic burden among persistent patients with $\mathrm{CHB}$ versus those who are not. The primary objectives of this study were to describe the patient characteristics, utilization, and costs among a cohort of CHB-infected US veterans treated with NAs (stratified by the coinfection and persistence). The secondary objectives included describing the medical resource utilization costs among persistent and non-persistent CHB-infected patients using an inception cohort with no prior NAs use. The inception cohort was created to mitigate the risk of misclassifying NA-treated patients with HIV co-infection and prior NA use.

\section{METHODS}

\section{Study Design and Data Source}

This was a retrospective study using medical, pharmacy, and enrollment records from the Veterans Health Administration (VHA) database from April 1, 2013 to March 31, 2018. The VHA is the largest integrated health care system in the USA, providing care for veterans and their families across the country. In addition, veterans have a 2- to 3-fold higher prevalence of $\mathrm{CHB}$ infection compared to the general US population [18-20]. The inpatient data contains information for each hospital admission including primary diagnosis at admission, type of discharge, and length of stay (LOS), whereas the outpatient files contain outpatient visit, procedure, and diagnosis costs. The VHA Decision Support System consists of laboratory test utilization and cost information related to inpatient and outpatient, pharmacy, and radiology services [21].

\section{Compliance with Ethics Guidelines}

This retrospective database analysis did not involve the collection, use, or transmittal of individual identifiable data. As such, institutional review board approval to conduct this study was not required and is considered exempt according to 45CFR46.101(b)(4): Existing Data $\&$ Specimens-No Identifiers. Both the data set itself and the security of the offices where the data are housed meet the requirements of the Health Insurance Portability and Accountability Act of 1996.

\section{Patient Selection}

\section{Overall Cohort}

Adult patients (aged 18 years or more) with at least two medical claims for CHB (International Classification of Disease, 9th Revision, Clinical Modification [ICD-9-CM] codes 070.22, 070.23, 070.32, 070.33, V02.61; ICD-10-CM: B18.0, B18.1, Z22.51) were identified between April 1, 2013 and March 31, 2018. The first observed CHB diagnosis date during the observation period in the VHA database was identified as the index diagnosis date. Patients were included if they had at least one pharmacy claim for a NA on or after the index diagnosis date through March 31, 2017. NAs included treatment with lamivudine (LAM), adefovir (ADV), entecavir (ETV), telbivudine (TBV), and tenofovir (TDF). The first NA prescription date was designated as the index date. Patients were required to have continuous VHA health plan enrollment with medical and pharmacy benefits for at least 6 months prior to (baseline period) and at least 12 months post index date (follow-up period). Patient data was assessed until the earliest of health plan disenrollment, death, or the end of the study period. Incident patients with $\mathrm{CHB}$ were excluded from the study if they had at least one medical claim for cirrhosis, HCC, liver failure, or liver transplantation in the 6 months prior to the index date, since these liver outcomes may be an indication of advanced liver disease (Fig. 1). 


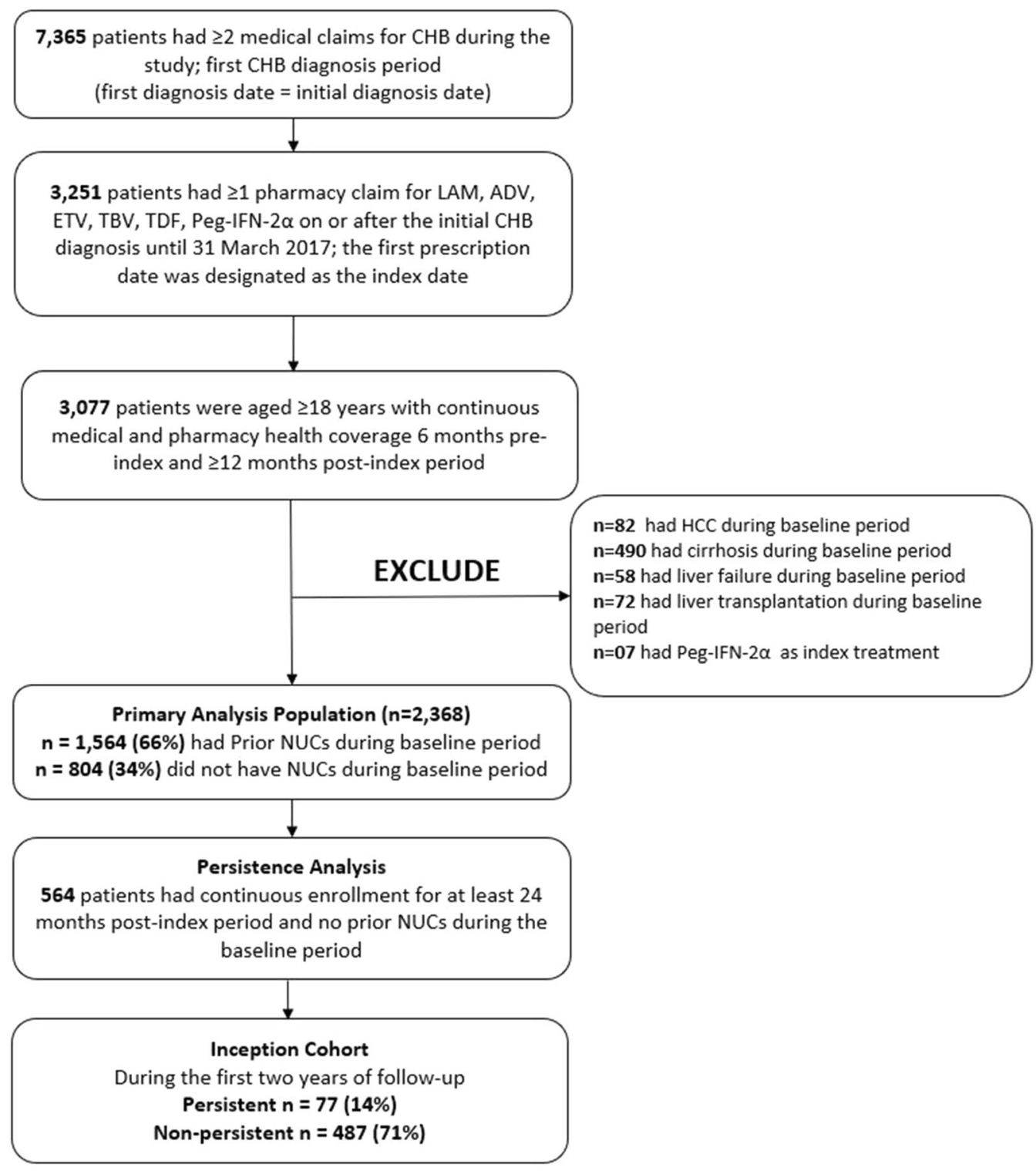

Fig. 1 Patient selection flow diagram. ADV adefovir, CHB chronic hepatitis B, ETV entecavir, HCC hepatocellular carcinoma, LAM lamivudine, NAs nucleos(t)ide analogues, Peg-IFN-2 $\alpha$ pegylated interferon, TBV telbivudine, TDF tenofovir

inception cohort were required to have (1) at least 24 months of continuous VHA health plan enrollment with medical and pharmacy benefits post index date; and (2) no evidence of pharmacy claims for a NA during the 6 months or more prior to index date. Two years was the longest follow-up period that yielded a large enough sample size to capture the economic outcomes associated with NA persistence. Among the inception cohort, patients were 
classified as persistent vs non-persistent. The persistent and non-persistent cohorts were created on the basis of treatment persistence of the index NA. Persistence to index therapy was defined on the basis of a 30-day discontinuation gap. If there was a gap of longer than 30 days between two NA prescriptions, then the patient was assigned to the non-persistent cohort; otherwise, the patient was considered persistent to their index NA.

\section{Study Variables}

\section{Baseline Variables}

Baseline and clinical characteristics during the 6 months prior to the index date were measured. Baseline characteristics included demographic (age, sex, race) and clinical characteristics (Charlson comorbidity index [CCI] score, and individual comorbid conditions identified via ICD-9-CM and ICD-10-CM codes). The CCI score is a weighted summation of 19 conditions and assigns a weight ranging from 1 to 6 according to disease severity [22]. Laboratory test values including HBV DNA ( $>1 \mathrm{million} \mathrm{IU} / \mathrm{ml}, \geq 20,000 \mathrm{IU} / \mathrm{ml},<2000 \mathrm{IU} /$ $\mathrm{ml}$, and $\geq 2000 \mathrm{IU} / \mathrm{ml}$ ), alanine aminotransferase (ALT), presence of hepatitis B e-antigen (HBeAg), and hepatitis B surface antigen (HBsAg) were evaluated if at least one value was recorded during \pm 90 days of the index date. FIB-4 is an index used to determine fibrosis level and is calculated from age, aspartate aminotransferase (AST), ALT, and platelet levels using the value closest to the index date ( \pm 90 days of the index date). The FIB- 4 score was calculated using the following formula: (Age $\times$ AST)/ (Platelet $\times \sqrt{ }$ ALT). In addition, a cutoff of less than 1.45 and greater than 3.25, which has shown a sensitivity of $70 \%$ and a specificity of $97 \%$ in the literature, was used [23]. Other baseline variables including co-diagnosis with hepatitis C, hepatitis D, HIV/AIDS, and baseline health care costs and utilization during the 6-month baseline period were evaluated.

\section{Outcomes Variables}

All-cause health care costs and resource utilization per patient per year (PPPY) were evaluated among the overall cohort patients during the follow-up period. To account for different follow-up periods, health care costs and utilization were annualized by dividing the sum by month of follow-up and multiplied by 12 . All-cause health care costs and resource utilization during year 1 of follow-up and during the entire first 2 years of follow-up were then evaluated using the inception cohort. The number of patients utilizing health care services was calculated, including the number of inpatient admissions, number of inpatient days (across all hospitalization), number of outpatient visits, and number of pharmacy claims. The calculated costs were comprised of inpatient, outpatient, pharmacy, and total costs (inpatient + outpatient + pharmacy). Costs were adjusted to 2018 US dollars using the medical care component of the Consumer Price Index (CPI).

\section{Statistical Methods}

Statistical analyses were conducted using Statistical Analysis System (SAS) v.9.3. (Cary, North Carolina, USA). All study variables were examined descriptively for patients in the overall cohort. For the inception cohort, all study variables were assessed and compared between persistent vs non-persistent patients during the first 2 years of the follow-up period. Percentages and counts were provided for categorical variables. Means and standard deviations (SDs) were computed for continuous variables. $p$ values were calculated according to the chi-square test for categorical variables; $t$ tests were used for continuous variables.

A generalized linear model (GLM) with loglink and a gamma-distribution was applied to compare adjusted all-cause health costs and utilization between persistent and non-persistent cohorts. Since a large proportion of zeros usually exist in health care cost variables such as inpatient admissions, length of stay (LOS), and inpatient costs, two-part models were implemented, in which the first part is a logistic regression of any service use, and the second part a GLM regression of cost [24]. On the basis of model fitting and to control for confounders, the following variables were controlled in the 
GLM model: age, sex, race, baseline comorbidities (atherosclerosis, malignancy, diabetes mellitus, chronic kidney disease, alcohol abuse/ dependence, hypertension, and non-alcoholic fatty liver disease [NAFLD]), and co-diagnoses with hepatitis C, D, or HIV/AIDS. The level of significance for $p$ values was set at $\alpha$-level 0.05 .

\section{RESULTS}

\section{Overall Cohort}

A total of 3077 US veterans aged 18 years or more were infected with $\mathrm{CHB}$ and had an index NA treatment between the CHB diagnosis date and March 31, 2017. From this sample, 702 patients were excluded because they had a diagnosis of cirrhosis, liver failure, HCC, or liver transplant during the 6-month baseline period. Additionally, seven patients treated with peginterferon alfa were excluded. After application of the inclusion and exclusion criteria, the final analytical sample comprised an overall cohort of 2368 patients treated with NAs (Fig. 1).

Among these patients, 1564 (66\%) had evidence of prior use of NAs during the baseline period, 1428 (60.3\%) patients were CHB monoinfected and 748 (32\%) patients were co-infected with HIV (Fig. 2).

In addition, $298(12.6 \%)$ patients were codiagnosed with hepatitis C, and 54 (2.3\%) were co-diagnosed with hepatitis $\mathrm{D}$ during the baseline period (results not shown).

\section{Baseline Characteristics}

Table 1 illustrates the baseline characteristics of the overall NA-treated patients, stratified by CHB mono-infection and HIV co-infection.

The mean age of the overall NA-treated patients was 58.1 years; $40.4 \%$ were White and $41.8 \%$ were Black. Most identified patients were men (96\%), which was expected given that VHA beneficiaries consist of a predominantly male population. The average CCI score of the overall NA-treated patients was 3.7. HBV DNA and ALT tests were performed in $52.4 \%$ and $89.1 \%$ of the overall cohort, respectively. Most patients had evidence of $\mathrm{HBV}$ DNA $\geq 2000 \mathrm{IU} / \mathrm{ml}$ (41.9\%) with an average ALT level of 50.2 U/l. Among patients that had a lab value for HBsAg, nearly $30 \%$ tested HBsAg positive (among 884 patients that had a claim for HBsAg \pm 90 days from the index date). Chronic kidney disease (CKD) and alcohol abuse/dependence occurred, respectively, in $13.2 \%$ and $11.8 \%$ of all NA-treated patients. The proportions of patients with malignancy, diabetes, hypertension, atherosclerosis, and non-alcoholic fatty liver disease (NAFLD) were $11.7 \%, 20.9 \%, 43.6 \%$, $6.9 \%$, and $2.0 \%$, respectively.

The CHB mono-infected and HIV co-infected patients had similar age. The CCI scores were higher among HIV co-infected patients (7.4 vs 1.9) compared to $\mathrm{CHB}$ mono-infected patients. HBeAg testing was conducted in $32.2 \%$ of patients with a higher proportion of $\mathrm{CHB}$ mono-infected patients who tested HBeAg negative $(25.3 \%$ vs $7.0 \%)$ than HIV co-infection patients. The proportion of patients with a FIB score greater than 3.25 was higher in $\mathrm{CHB}$ mono-infected $(11.1 \%$ vs $9.1 \%)$ than HIV coinfected patients. These laboratory test results should be interpreted with caution given that they were evaluated using one result value that was recorded closest to \pm 90 days of the index date. Rates of malignancy (9.6\% vs $12.5 \%)$, hypertension (36.1\% vs $45.9 \%)$, and diabetes mellitus (14.5\% vs $24.3 \%)$ were lower in HIV coinfected patients compared to CHB mono-infected patients. During the baseline period, HIV co-infected patients utilized more health care resources, which resulted in increased overall total costs vs CHB mono-infected patients.

\section{Unadjusted Follow-up Health Care Utilization and Costs PPPY}

On average, all NA-treated patients had 0.3 inpatient admissions, 23.4 outpatient visits, and 30.6 prescription claims. Total costs PPPY for overall NAs treated were $\$ 39,240$ (Fig. 3).

CHB mono-infected patients had fewer inpatient admissions ( 0.3 vs 0.5$)$, shorter inpatient LOS (2.8 days vs 6.4 days), and fewer prescription claims (28.1 vs 34.2) PPPY than HIV co-infected patients (Fig. 3). CHB mono-infected patients incurred average total costs PPPY of $\$ 29,957$ vs $\$ 55,220$ in HIV co-infected patients. The main cost differences between 


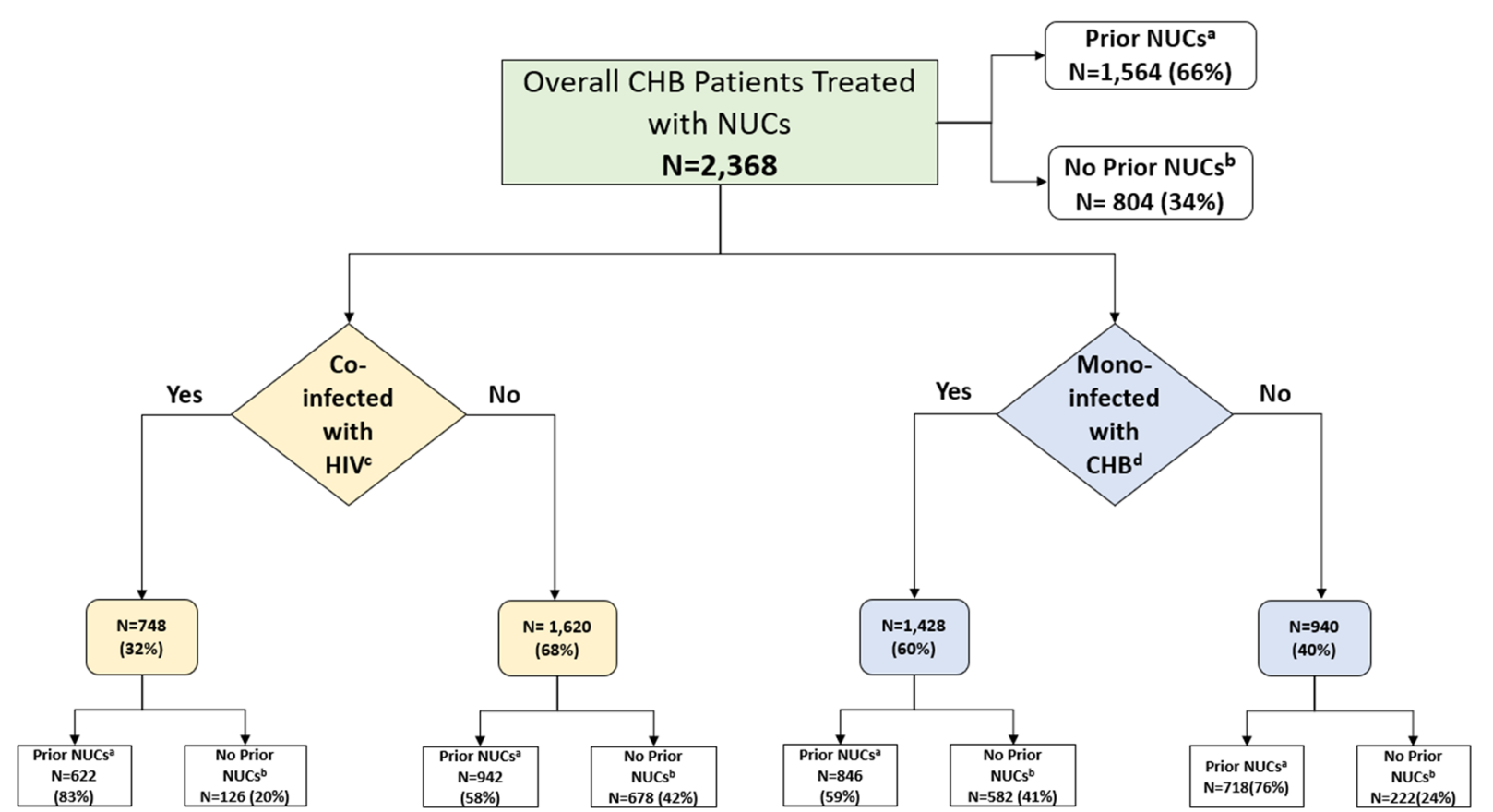

Fig. 2 Overall NA-treated chronic hepatitis B patients with and without baseline NA utilization. $\mathrm{CHB}$ chronic hepatitis B, HIV human immunodeficiency virus, NAs nucleos(t)ide analogues. ${ }^{a}$ Patients with $\geq 1$ pharmacy claim for LAM, ADV, ETV, TBV, or TDF 6 months pre index date. ${ }^{b}$ Patients without $\geq 1$ pharmacy claim for

CHB mono-infected and HIV co-infected were higher inpatient costs ( $\$ 7072$ vs $\$ 12,845$ PPPY) and pharmacy costs ( $\$ 9529$ vs $\$ 22,977$ PPPY) in HIV co-infected patients (Fig. 3).

\section{Inception Cohort}

Among patients with at least 2 years of followup, 164 (29\%) were persistent and 400 (71\%) were non-persistent to their NA during the first year. Persistence decreased over time with only 77 (14\%) patients who were persistent and 487 (86\%) patients who were non-persistent to their NA during the first 2-year follow-up period (Fig. 1).

\section{Patient Characteristics}

Supplemental Table 1 presents the baseline characteristics among persistent vs non-persistent patients during the 2-year follow-up period. Persistent and non-persistent patients were

similar in age. Rates of malignancy $(10.45 \%$ vs $11.1 \%)$, diabetes mellitus (16.9\% vs $18.5 \%)$, chronic kidney disease (5.2\% vs $11.5 \%$ ), alcohol abuse/dependence $(9.1 \%$ vs $14.2 \%)$, hypertension ( $41.6 \%$ vs $43.9 \%)$, and co-diagnosis with hepatitis C, D, or HIV/AIDS (23.4\% vs $27.3 \%$ ) were non-significantly lower among persistent patients compared to non-persistent patients. Persistent patients had a significantly lower number of inpatient admissions (0.1 vs 0.3 ), shorter inpatient LOS (1.3 vs 3.7), and lower inpatient ( $\$ 1632$ vs $\$ 8064)$ and total costs (\$7369 vs $\$ 16,522)$ compared to non-persistent patients.

\section{Follow-up All-cause Health Care Utilization and Costs}

A summary of all-cause health care costs and utilization between the persistent and nonpersistent patients is presented in Table 2 . In these descriptive analyses, compared to non- 
Table 1 Patient demographic and clinical characteristics among overall NA-treated patients: mono-infected with CHB and co-infected with HIV subgroups

\begin{tabular}{|c|c|c|c|}
\hline & $\begin{array}{l}\text { Overall NA-treated } \\
\text { patients } \\
N=2368\end{array}$ & $\begin{array}{l}\text { Mono-infected with } \\
\text { CHB } \\
N=1428\end{array}$ & $\begin{array}{l}\text { Co-infected with } \\
\text { HIV } \\
N=748\end{array}$ \\
\hline \multicolumn{4}{|l|}{ On the index date } \\
\hline Age, mean $(\mathrm{SD})$ & $58.1(12.5)$ & $58.9(14.3)$ & $56.9(9.0)$ \\
\hline \multicolumn{4}{|l|}{ Age group (years), $n(\%)$} \\
\hline $18-34$ & $105(4.4 \%)$ & $94(6.6 \%)$ & $6(0.8 \%)$ \\
\hline $35-54$ & $713(30.1 \%)$ & $382(26.8 \%)$ & $284(38.0 \%)$ \\
\hline $55-64$ & $835(35.3 \%)$ & $414(29.0 \%)$ & $316(42.2 \%)$ \\
\hline $65+$ & $715(30.2 \%)$ & $538(37.7 \%)$ & $142(19.0 \%)$ \\
\hline \multicolumn{4}{|l|}{ Sex, $n(\%)$} \\
\hline Male & $2272(95.9 \%)$ & $1342(94.0 \%)$ & $742(99.2 \%)$ \\
\hline Female & $96(4.1 \%)$ & $86(6.0 \%)$ & $6(0.8 \%)$ \\
\hline \multicolumn{4}{|l|}{ Race, $n(\%)$} \\
\hline White & $956(40.4 \%)$ & $570(39.9 \%)$ & $293(39.2 \%)$ \\
\hline Black & $989(41.8 \%)$ & $524(36.7 \%)$ & $395(52.8 \%)$ \\
\hline Other & $300(12.7 \%)$ & $256(17.9 \%)$ & $25(3.3 \%)$ \\
\hline Unknown & $123(5.2 \%)$ & $78(5.5 \%)$ & $35(4.7 \%)$ \\
\hline \multicolumn{4}{|l|}{ On the index date \pm 90 days } \\
\hline \multicolumn{4}{|l|}{ Index laboratory values } \\
\hline HBV DNA levels, $n(\%)^{\mathrm{a}}$ & $1240(52.4 \%)$ & $829(58.1 \%)$ & $303(40.5 \%)$ \\
\hline$>1$ million $\mathrm{IU} / \mathrm{ml}$ & $131(5.5 \%)$ & $93(6.5 \%)$ & $24(3.2 \%)$ \\
\hline$\geq 20,000 \mathrm{IU} / \mathrm{ml}$ & $64(2.7 \%)$ & $40(2.8 \%)$ & $19(2.5 \%)$ \\
\hline$\geq 2000 \mathrm{IU} / \mathrm{ml}$ & $992(41.9 \%)$ & $659(46.1 \%)$ & $250(33.4 \%)$ \\
\hline$<2000 \mathrm{IU} / \mathrm{ml}$ & $53(2.2 \%)$ & $37(2.6 \%)$ & $10(1.3 \%)$ \\
\hline ALT Levels, $n(\%)$ & $2109(89.1 \%)$ & $1251(87.6 \%)$ & $682(91.2 \%)$ \\
\hline $\begin{array}{l}\text { Mean (among patients with ALT records), } \\
\text { (SD) }\end{array}$ & $50.2(84.1)$ & $53.9(94.3)$ & $38.2(43.8)$ \\
\hline $\mathrm{HBsAg}, n(\%)^{\mathrm{a}}$ & $844(35.6 \%)$ & $583(40.8 \%)$ & $178(23.8 \%)$ \\
\hline Positive & $706(29.8 \%)$ & $510(35.7 \%)$ & $132(17.6 \%)$ \\
\hline Negative & $138(5.8 \%)$ & $73(5.1 \%)$ & $46(6.1 \%)$ \\
\hline $\mathrm{HBeAg}, n(\%)^{\mathrm{a}}$ & $762(32.2 \%)$ & $566(39.6 \%)$ & $115(15.4 \%)$ \\
\hline Positive & $303(12.8 \%)$ & $205(14.4 \%)$ & $63(8.4 \%)$ \\
\hline Negative & $459(19.4 \%)$ & $361(25.3 \%)$ & $52(7.0 \%)$ \\
\hline
\end{tabular}


Table 1 continued

\begin{tabular}{|c|c|c|c|}
\hline & $\begin{array}{l}\text { Overall NA-treated } \\
\text { patients } N=2368\end{array}$ & $\begin{array}{l}\text { Mono-infected with } \\
\text { CHB } N=1428\end{array}$ & $\begin{array}{l}\text { Co-infected with } \\
\text { HIV } N=748\end{array}$ \\
\hline Fibrosis level, $n(\%)^{\mathrm{a}}$ & $1902(80.3 \%)$ & $1092(76.5 \%)$ & $648(86.6 \%)$ \\
\hline $\mathrm{F}<1.45$ & $812(34.3 \%)$ & $468(32.8 \%)$ & $281(37.6 \%)$ \\
\hline $\mathrm{F}>3.25$ & $253(10.7 \%)$ & $159(11.1 \%)$ & $68(9.1 \%)$ \\
\hline \multicolumn{4}{|l|}{6 months pre index date (baseline period) } \\
\hline $\begin{array}{l}\text { Charlson comorbidity index score, mean } \\
\text { (SD) }\end{array}$ & $3.7(3.1)$ & $1.9(1.7)$ & $7.4(2.0)$ \\
\hline \multicolumn{4}{|l|}{ Baseline comorbidities, $n$ (\%) } \\
\hline Malignancy & $277(11.7 \%)$ & $178(12.5 \%)$ & $72(9.6 \%)$ \\
\hline Diabetes mellitus & $496(20.9 \%)$ & $347(24.3 \%)$ & $108(14.4 \%)$ \\
\hline Chronic kidney disease & $312(13.2 \%)$ & $163(11.4 \%)$ & $118(15.8 \%)$ \\
\hline Alcohol abuse/dependence & $279(11.8 \%)$ & $135(9.5 \%)$ & $100(13.4 \%)$ \\
\hline Hypertension & $1032(43.6 \%)$ & $655(45.9 \%)$ & $270(36.1 \%)$ \\
\hline Atherosclerosis & $163(6.9 \%)$ & $100(7.0 \%)$ & $47(6.3 \%)$ \\
\hline Non-alcoholic fatty liver disease & $48(2.0 \%)$ & $38(2.7 \%)$ & $7(0.9 \%)$ \\
\hline \multicolumn{4}{|c|}{ Baseline all-cause health care utilization, mean (SD) } \\
\hline No. inpatient admissions & $0.2(0.7)$ & $0.2(0.6)$ & $0.3(0.8)$ \\
\hline No. inpatient days & $2.8(12.4)$ & $1.8(10.5)$ & $4.1(14.4)$ \\
\hline No. outpatient visit & $12.1(11.8)$ & $11.5(10.7)$ & $12.3(12.8)$ \\
\hline No. prescription claims & $14.7(16.3)$ & $13.3(15.6)$ & $16.6(16.7)$ \\
\hline \multicolumn{4}{|c|}{ Baseline all-cause health care costs, mean (SD) } \\
\hline Inpatient costs & $\$ 6771(\$ 28,133)$ & $\$ 5109(\$ 26,912)$ & $\$ 9404(\$ 31,437)$ \\
\hline Outpatient costs & $\$ 7585(\$ 9253)$ & $\$ 6354(\$ 7984)$ & $\$ 8869(\$ 9651)$ \\
\hline Pharmacy costs & $\$ 4565(\$ 10,530)$ & $\$ 3039(\$ 11,407)$ & $\$ 7227(\$ 6828)$ \\
\hline
\end{tabular}

$A L T$ alanine aminotransferase, $C H B$ chronic hepatitis $\mathrm{B}, H B e A g$ hepatitis $\mathrm{B}$ e-antigen, $H B s A g$ hepatitis $\mathrm{B}$ surface antigen, $H B V$ hepatitis B virus, $N A s$ nucleos $(\mathrm{t})$ ide analogues, $S D$ standard deviation

${ }^{a}$ Laboratory tests were evaluated using one laboratory test result value recorded the closest to \pm 90 days of the index date. Not all patients had a claim for these laboratory tests. Therefore, the results should be interpreted with caution

persistent patients, persistent patients had significantly fewer inpatient admissions during first year follow-up (0.2 vs 0.4$)$ or first 2 years of follow-up (0.4 vs 0.8) of treatment. Persistent patients also had fewer days in the hospital during the first year (1.6 vs 5.6 days) or first
2 years (3.1 vs 11.4 days) (all $p<0.05$ ) of treatment. Consequently, the persistent patients incurred lower cumulative all-cause health care costs during the first year ( $\$ 31,971$ vs $\$ 38,340$; $p=0.217)$ and the first 2 years of follow-up $(\$ 61,712$ vs $\$ 70,493 ; p=0.284)$, with net cost 


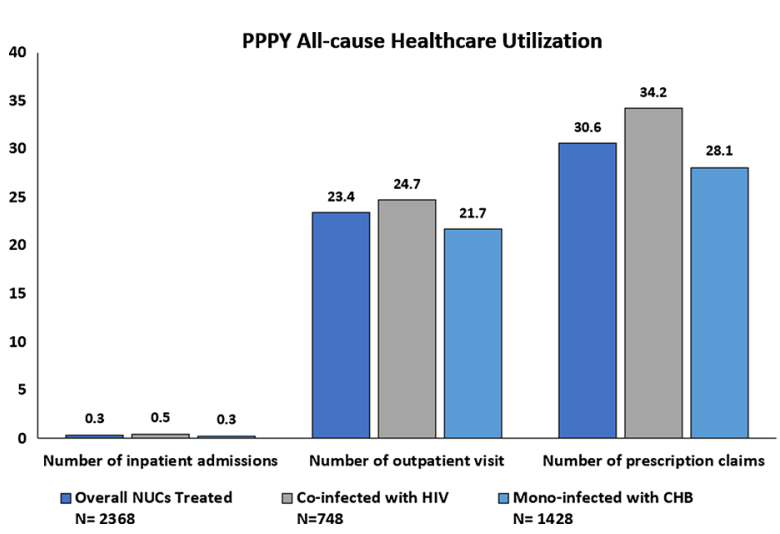

Fig. 3 Unadjusted health care costs and utilization among overall NA-treated patients stratified by mono-infected with $\mathrm{CHB}$ and the co-infected with HIV subgroups. $\mathrm{CHB}$

savings of $\$ 8781$ at 2 years compared to nonpersistent patients. However, the differences in the overall health care costs were not statistically significant. After adjustment for baseline demographic and clinical characteristics using GLM, persistent patients had a significantly lower average number of inpatient admissions during the first year ( 0.2 vs 0.4$)$ and during the first 2 years (0.4 vs 0.8 ) and had fewer days in the hospital during the first year (3.1 vs 5.6 days) and during the first 2 years (5.3 vs 11.4 days) compared to non-persistent (all $p<0.05)$. Similarly, persistent patients were associated with lower overall health care costs during the first year $(\$ 1198 ; p>0.05)$ and first 2 years $(\$ 851 ; p>0.05)$ of follow-up compared to non-persistent patients. The primary costs drivers for non-persistent patients were inpatient costs, which cumulatively increased by $\$ 7889(p=0.001)$ during the first 2 years compared to persistent patients. The higher pharmacy costs in persistent patients were offset by lower inpatient costs.

\section{DISCUSSION}

This study was conducted to better characterize CHB-infected patients and quantify the relationship between NA persistence and economic outcomes using real-world data from the VHA database. $\mathrm{CHB}$ was observed to be associated with considerable clinical and economic

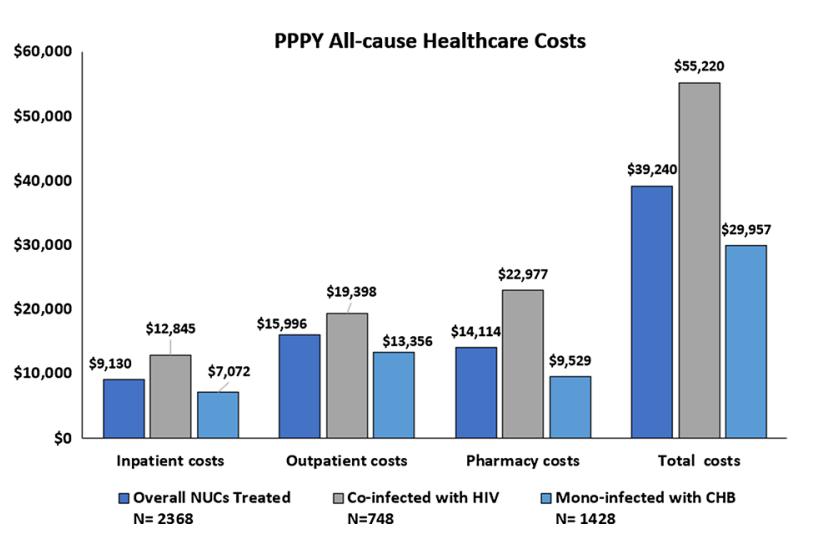

chronic hepatitis $\mathrm{B}, \mathrm{NA}$ nucleos $(\mathrm{t})$ ide analogues, PPPY per patient per year

burden. About $60 \%$ of the overall cohort of NAtreated patients were $\mathrm{CHB}$ mono-infected, whereas $32 \%$ of the sample was co-infected with HIV. Similarly, Moorman et al. [25] found that $31.7 \%$ of patients with $\mathrm{CHB}$ analyzed from electronic medical records of an integrated health care system in the USA were co-infected with HIV. In the current analysis, patients treated with NAs had a greater proportion of complications and infections including hypertension, diabetes mellitus, chronic kidney disease, malignancy, and alcohol abuse/ dependence, particularly in the CHB mono-infected patients vs HIV co-infected patients. One possible explanation for these findings is that our study may have captured a cohort of patients with $\mathrm{CHB}$ with longer disease duration. However, the exact disease duration was unknown given that the study sample included a prevalent $\mathrm{CHB}$ cohort. In addition, HIV coinfected patients may seek care more frequently as part of their HIV management which may result in additional preventative care compared to $\mathrm{CHB}$ mono-infected patients.

To explore the disease burden of $\mathrm{CHB}$, baseline characteristics of mono-infected CHB treated patients were examined. These patients had fewer comorbidities and incurred lower allcause heath costs compared to overall NA-treated patients. The subgroup of HIV co-infected patients had higher CCI scores and higher disease severity compared to the overall NA-treated patients, resulting in higher baseline heath care 
Table 2 Follow-up unadjusted and adjusted health care resource utilization and costs among persistent and non-persistent patients in the VHA population

\begin{tabular}{|c|c|c|c|c|c|c|}
\hline & $\begin{array}{l}\text { Persistent } \\
N=77 \\
\text { Unadjusted } \\
\text { mean }\end{array}$ & $\begin{array}{l}\text { Non- } \\
\text { persistent } \\
N=487 \\
\text { Unadjusted } \\
\text { mean }\end{array}$ & $\begin{array}{l}\text { Unadjusted } \\
p \text { value }\end{array}$ & $\begin{array}{l}\text { Persistent } \\
N=77 \\
\begin{array}{l}\text { Adjusted } \\
\text { mean }\end{array}\end{array}$ & $\begin{array}{l}\text { Non- } \\
\text { persistent } \\
N=487 \\
\text { Adjusted } \\
\text { mean }\end{array}$ & $\begin{array}{l}\text { Adjusted } \\
p \text { value }\end{array}$ \\
\hline \multicolumn{7}{|c|}{ Follow-up all-cause health care utilization: first year } \\
\hline $\begin{array}{l}\text { No. inpatient } \\
\text { admissions }\end{array}$ & 0.2 & 0.4 & 0.005 & 0.2 & 0.4 & $<0.0001$ \\
\hline No. inpatient days & 1.6 & 5.6 & 0.003 & 3.1 & 5.6 & 0.0482 \\
\hline No. outpatient visits & 20.0 & 24.9 & 0.047 & 20.7 & 22.8 & 0.3161 \\
\hline $\begin{array}{l}\text { No. prescription } \\
\text { claims }\end{array}$ & 27.1 & 27.8 & 0.769 & 27.5 & 25.1 & 0.305 \\
\hline \multicolumn{7}{|c|}{ Follow-up all-cause health care costs: first year } \\
\hline Inpatient costs & $\$ 4455$ & $\$ 9813$ & 0.035 & $\$ 7740$ & $\$ 9714$ & 0.224 \\
\hline Outpatient costs & $\$ 14,172$ & $\$ 16,951$ & 0.292 & $\$ 13,250$ & $\$ 14,854$ & 0.1442 \\
\hline Pharmacy costs & $\$ 13,344$ & $\$ 11,575$ & 0.318 & $\$ 11,937$ & $\$ 10,071$ & 0.2461 \\
\hline Total costs & $\$ 31,971$ & $\$ 38,340$ & 0.217 & $\$ 30,679$ & $\$ 31,877$ & 0.1386 \\
\hline \multicolumn{7}{|c|}{ Follow-up all-cause health care utilization: first 2 years } \\
\hline $\begin{array}{l}\text { No. inpatient } \\
\text { admissions }\end{array}$ & 0.4 & 0.8 & 0.012 & 0.4 & 0.8 & $<0.0001$ \\
\hline No. inpatient days & 3.1 & 11.4 & 0.002 & 5.3 & 11.4 & 0.002 \\
\hline No. outpatient visits & 37.0 & 47.1 & 0.016 & 37.7 & 43.2 & 0.1424 \\
\hline $\begin{array}{l}\text { No. prescription } \\
\text { claims }\end{array}$ & 51.9 & 53.2 & 0.783 & 52.6 & 47.5 & 0.2609 \\
\hline \multicolumn{7}{|c|}{ Follow-up all-cause health care costs: first 2 years } \\
\hline Inpatient costs & $\$ 7274$ & $\$ 19,011$ & 0.002 & $\$ 10,594$ & $\$ 18,483$ & 0.001 \\
\hline Outpatient costs & $\$ 27,633$ & $\$ 30,613$ & 0.507 & $\$ 25,367$ & $\$ 27,229$ & 0.4038 \\
\hline Pharmacy costs & $\$ 26,805$ & $\$ 20,869$ & 0.048 & $\$ 23,664$ & $\$ 18,135$ & 0.0412 \\
\hline Total costs & $\$ 61,712$ & $\$ 70,493$ & 0.284 & $\$ 58,450$ & $\$ 59,301$ & 0.2781 \\
\hline
\end{tabular}

VHA Veterans Health Administration

costs which could be as a result of receiving care for HIV infection.

HBV DNA quantification is a useful marker for diagnosis of $\mathrm{CHB}$ and the presence of HBsAg for at least 6 months is used to define chronic vs acute conditions. The AASLD recommends that ALT and HBsAg levels are measured at least every 6 months for patients with CHB. In our study, the frequency of testing was much lower, and only $52.4 \%, 89.1 \%, 35.6 \%$, and $32.2 \%$ of 
patients were found to have had at least one HBV DNA, ALT, HBsAg, and HBeAg test, respectively, during the 6-month baseline period. Previous studies have shown that patients had laboratory tests at lower frequency than the recommended guidelines which might result in underdiagnosis of CHB [26]. This may delay initiation of antiviral therapy, leaving patients at risk for disease progression and potentially leading to higher economic burden associated with the disease. Among patients with $\mathrm{CHB}$ who had available laboratory tests, the number of patients with $\mathrm{CHB}$ that had an undetectable viral load was relatively low in our study which could be an indication of limited effectiveness of NAs in the real-world settings or persistence concerns that could have led to non-occurrence of HBV DNA suppression. However, caution should be exercised when interpreting these data given that only one laboratory test value recorded within 90 days of the index date was used to capture HBV DNA values.

Most studies in the literature have evaluated the cost-effectiveness of immunization or treatment interventions for CHB $[27,28]$. Yuan et al. [29] reported the annual costs associated with various liver outcomes among patients prescribed LAM and ETV. Estimates in 2006 were $\$ 1130$ ( $\$ 1408$ in 2018) for compensated cirrhosis, $\$ 15,085 \quad(\$ 18,790$ in 2018) for decompensated cirrhosis, and \$9923 $(\$ 12,359$ in 2018) for HCC in the USA. In our study, the unadjusted costs among overall NA-treated patients were $\$ 39,240 \mathrm{PPPY}$. Expenditures were lower among mono-infected patients with $\mathrm{CHB}$ (\$29,957 PPPY) and higher among those co-infected with HIV (\$55,220 PPPY). Patients coinfected with HIV had greater disease severity and CCI scores compared to the mono-infected CHB population, which may have contributed to the higher costs among these patients.

Overall, we observed suboptimal persistence to NA current standard of care and a decrease in persistence over time. Our data demonstrated a $29 \%$ NA persistence level during year 1 of follow-up, which decreased to $14 \%$ during year 2 of follow-up. Although most of the published literature on $\mathrm{CHB}$ treatment has evaluated adherence [30-32], and indicated trends similar to those observed in our study with suboptimal adherence and a decrease in adherence overtime, Chotiyaputta, et al. reported that persistence decreased to $94.2 \%$ after 3 months, $77.6 \%$ after 6 months, $74.7 \%$ after 9 months, and $73.4 \%$ after 12 months on medication among patients with $\mathrm{CHB}$ with no prior exposure to NAs [33].

Current guidelines for CHB therapy recommend continued treatment with NAs to achieve better outcomes [34]. Chronic lifelong treatments may lead to a drop in persistence over time as observed in our study (decreased NA persistence after the 2-year follow-up period). These results are consistent with previous results reported in other chronic conditions which have reported a decrease in the rate of patients who persistently adhere to the prescribed medication for a chronic condition, particularly within the first 6 months of therapy [35-38]. Further research is needed to confirm this trend in patients with longer follow-up time.

In the current study, multiple factors may be associated with non-persistence or discontinuation including occurrence of adverse events, death, or receipt of care outside the VHA system. In addition, approximately $27-32 \%$ of patients in this analysis were at least 65 years of age. There is a possibility that these patients received care through Medicare and hence their complete medical and treatment history may not have been captured.

This study demonstrated that maintaining persistence to NAs for at least 2 years is associated with fewer inpatient admissions, lower hospital LOS, and lower overall health care costs compared to patients with $\mathrm{CHB}$ who were nonpersistent to NAs in the first 2 years of followup. After adjustment for potential confounders, the results of this study suggest that savings could be generated for patients with $\mathrm{CHB}$ who remain persistent to their index NA for at least 2 years, particularly for inpatient costs (\$7889). This could also represent a significant clinical and economic burden for those patients that require lifelong treatment with the current standard of care. The reduced inpatient costs were offset by the higher pharmacy costs among NA-persistent patients resulting in a net overall 
cost savings of $\$ 851$ compared to non-persistent patients. The difference in cumulative overall total costs in 2 years did not meet statistical significance most likely because of the small sample size, particularly in persistent patients and limited follow-up time.

The unadjusted health care cost among persistent patients during the first 2 years was lower by $\$ 8781$ (non-significant) compared to non-persistent patients. Furthermore, persistent patients incurred significantly lower inpatient costs compared to those who were non-persistent. Non-persistent patients captured in this study incurred nearly double the inpatient costs of persistent patients. They also had a higher frequency of malignancies and mental health disorders (results not shown). The costs of comorbid conditions among non-persistent patients with $\mathrm{CHB}$ may explain the inpatient cost differences compared to persistent patients.

It is well documented in the literature that for many chronic diseases, treatment non-adherence is associated with increased morbidity, mortality (5.9\%), and substantial increased costs (ranging from $\$ 5271$ to $\$ 52,341$ ) [39, 40]. However, published literature regarding $\mathrm{CHB}$ is systematic reviews; direct comparisons to our study results are challenging because of differences in the study populations, study design, and/or varying definitions of persistence and adherence [41-43].

NAs have been the mainstay of treatment among patients with CHB. However, proper treatment with NAs is long term, and optimal persistence to treatment may be required to reach appropriate and desired treatment outcomes. As previously reported, many patients with $\mathrm{CHB}$ have difficulty with current longterm treatment persistence. These patients may benefit by having access to finite novel treatments that have the potential to provide a functional cure for $\mathrm{CHB}$ in a shorter period of time. Several treatment options are currently in clinical development with the goal of providing patients the ability to achieve a functional cure and sustained off-treatment response [44, 45]. Functional cure may also lead to additional benefits of further reducing long-term liver complications as well as reducing the overall health care utilization and costs associated with
CHB. Consequently, new innovative technologies, with higher rates of functional cure and favorable safety and tolerability profiles, are needed to address the current unmet need among patients with $\mathrm{CHB}$.

\section{Strengths and Limitations}

To the best of our knowledge, this is the first real-world analysis of US veterans with $\mathrm{CHB}$ that highlights the unmet treatment need using standard of care and evaluates the impact of persistence to NAs on economic outcomes. In addition, the VHA is a closed centralized system and is the largest health care provider for hepatitis care in the USA, providing an opportunity to examine economic burden among patients with CHB using a large data set. However, this study has several limitations. Only 5 years of VHA data was available for this analysis, which limits our ability to evaluate long-term outcomes (such as HBsAg loss and seroconversion, remission, HCC, liver failure, liver transplantation, cirrhosis) as well as complete patient history, date of first diagnosis, duration of $\mathrm{CHB}$ infection, or previous treatment prior to start date of available data. In addition, critical variables could increase the economic burden of $\mathrm{CHB}$ including factors associated with the response to treatment, burden associated with NA side effects, or CHB disease progression. These factors could not have been concluded with certainty as a result of the nature of the claims databases. Cumulative persistence to NAs was assessed during a 2-year follow-up period, which is a short duration for this purpose; therefore, a larger sample size and longer follow-up duration are necessary to more convincingly assess persistence over time. However, there is limited evidence of cumulative NA persistence from 2 years; future research should validate this data.

Laboratory data was limited which restricted our ability to assess variables such as disease severity or treatment response. These variables may have impacted the decision to continue treatment and consequently have substantial impact on the outcomes. Also, lab values were recorded within 90 days of the index date. 
Therefore, not all patients that were included in our analysis had a lab value for HBV DNA, ALT level, HBsAg, or fibrosis level. Medications dispensed over the counter, samples provided by a physician, and pharmacy claims in the inpatient setting cannot be observed in claims data. Hence, we could not evaluate the true cost associated with treating side effects of antiviral treatment. Moreover, since this analysis was conducted within the VHA system, which includes predominantly older white men in the USA with unique care delivery and reimbursement mechanisms, the findings may not be generalizable to other patients with $\mathrm{CHB}$ receiving care in different health care delivery systems, such as commercial managed care plans, Medicare, or Medicaid plans. In addition, the study does not reflect the costs for any health care services that were received outside of the VHA system and therefore may be another reason our study is not generalizable to the overall $\mathrm{CHB}$ population.

\section{CONCLUSION}

Our study provides a characterization of CHBinfected patients, burden of illness, health care utilization, and the relationship between persistence to NAs and related economic outcomes, which is lacking from studies reported to date. Furthermore, the findings of this study suggest that significant short-term cost savings could be generated for CHB-infected patients when they remain persistent to their NAs during the first 2 years of follow-up. It is important to understand the relationship between NA persistence and the economic burden associated with patients with $\mathrm{CHB}$ in order to help decision makers target the best treatment interventions as well as to allocate resources to reduce the burden of illness. The number of patients with $\mathrm{CHB}$ that had an undetectable viral load is relatively low. Thus, there is an unmet medical need for effective treatments that can help provide sustained HBsAg loss and, consequently, sustained undetectable viral load. The complexity of successful long-term treatment management of CHB underscores the need for more treatment options with a finite duration and sustained off-treatment response or functional cure; this will help to better manage $\mathrm{CHB}$ and improve treatment persistence rates, thereby aiding patients to achieve desired treatment benefits.

\section{ACKNOWLEDGEMENTS}

Funding. Sponsorship for this study and the Rapid and Open Access Fees were funded by Janssen Scientific Affairs, LLC. All authors had full access to all of the data in this study and take complete responsibility for the integrity of the data and accuracy of the data analysis.

Authorship. All named authors meet the International Committee of Medical Journal Editors (ICMJE) criteria for authorship for this article, take responsibility for the integrity of the work as a whole, and have given their approval for this version to be published.

Disclosures. Furaha Kariburyo is a paid employee of STATinMED Research which is a paid consultant to Janssen Scientific Affairs. Janvi Sah is a paid employee of STATinMED Research which is a paid consultant to Janssen Scientific Affairs. Lin Xie is a paid employee of STATinMED Research which is a paid consultant to Janssen Scientific Affairs. Urbano Sbarigia is employee of Janssen Pharmaceutica NV, Belgium. Shirley Sylvester is a paid employee of Johnson and Johnson. Jamie Colasurdo is a paid employee of Janssen Research and Development. Eva Katz is a paid employee of Janssen Research and Development. Urbano Sbarigia owns stock of Johnson and Johnson. Shirley Sylvester owns stock of Johnson and Johnson. Jamie Colasurdo owns stock of Johnson and Johnson. Eva Katz owns stock of Johnson and Johnson.

Compliance with Ethics Guidelines. This retrospective database analysis did not involve the collection, use, or transmittal of individual identifiable data. As such, institutional review board approval to conduct this study was not required and considered exempt according to 
45CFR46.101(b)(4): Existing Data \& Specimens-No Identifiers. Both the data set itself and the security of the offices where the data are housed meet the requirements of the Health Insurance Portability and Accountability Act of 1996.

Data Availability. The dataset supporting the conclusions in this article is available from the US Veterans Health Administration. However, restrictions apply to the availability of these data, which were used under license for the current study, and so are not publicly available.

Open Access. This article is licensed under a Creative Commons Attribution-NonCommercial 4.0 International License, which permits any non-commercial use, sharing, adaptation, distribution and reproduction in any medium or format, as long as you give appropriate credit to the original author(s) and the source, provide a link to the Creative Commons licence, and indicate if changes were made. The images or other third party material in this article are included in the article's Creative Commons licence, unless indicated otherwise in a credit line to the material. If material is not included in the article's Creative Commons licence and your intended use is not permitted by statutory regulation or exceeds the permitted use, you will need to obtain permission directly from the copyright holder. To view a copy of this licence, visit http:// creativecommons.org/licenses/by-nc/4.0/.

\section{REFERENCES}

1. Polaris Observatory Collaborators. Global prevalence, treatment, and prevention of hepatitis B virus infection in 2016: a modelling study. Lancet Gastroenterol Hepatol. 2018;3(6):383-403.

2. US Centers for Disease Control. Commentary: US 2014 surveillance data for viral hepatitis statistics \& surveillance division of viral hepatitis. 2019. https://www.cdc.gov/hepatitis/statistics/2014 surveillance/commentary.htm. Accessed 25 Apr 2019.
3. Cdc.gov. Statistics \& Surveillance Division of Viral Hepatitis, CDC. 2019. https://www.cdc.gov/ hepatitis/statistics/index.htm. Accessed 28 Apr 2019.

4. Sorrell MF, Belongia EA, Costa J, et al. National Institutes of Health consensus development conference statement: management of hepatitis B. Ann Intern Med. 2009;150(2):104-10.

5. Williams WW, Lu PJ, O'Halloran A, et al. Surveillance of vaccination coverage among adult populations-United States, 2015. MMWR Surveill Summ. 2017;66(11):1-28.

6. Lok AS, Zoulim F, Dusheiko G, Ghany MG. Hepatitis B cure: from discovery to regulatory approval. Hepatology. 2017;66(4):1296-313. https://doi.org/10.1002/hep.29323.

7. EASL. Clinical practice guidelines on the management of hepatitis B virus infection. J Hepatol. 2017;2017:370-98.

8. Terrault NA, Bzowej NH, Chang KM, et al. AASLD guidelines for treatment of chronic hepatitis B. Hepatology. 2016;63:261-83.

9. Hung $\mathrm{CH}$, Wang JH, Lu SN, Hu TH, Lee CM, Chen $\mathrm{CH}$. Hepatitis B surface antigen loss and clinical outcomes between HBeAg-negative cirrhosis patients who discontinued or continued nucleoside analogue therapy. J Viral Hepatitis. 2017;24(7): 599-607.

10. Dusheiko G, Wang B. Hepatitis B surface antigen loss: too little, too late and the challenge for the future. Gastroenterology. 2019;156(3):548-51.

11. Yeo YH, Ho HJ, Yang HI, et al. Factors associated with rates of HBsAg seroclearance in adults with chronic HBV infection: a systematic review and meta-analysis. Gastroenterology. 2019;156(3): 635-46.

12. Chang ML, Liaw YF, Hadziyannis SJ. Systematic review: cessation of long-term nucleos(t)ide analogue therapy in patients with hepatitis B e antigennegative chronic hepatitis B. Aliment Pharmacol Ther. 2015;42(3):243-57.

13. Fung J, Seto WK, Lai CL, Yuen MF. Extrahepatic effects of nucleoside and nucleotide analogues in chronic hepatitis B treatment. J Gastroenterol Hepatol. 2014;29(3):428-34.

14. Moreno-Cubero E, del Arco RTS, Peña-Asensio J, de Villalobos ES, Míquel J, Larrubia JR. Is it possible to stop nucleos(t)ide analogue treatment in chronic hepatitis B patients? World J Gastroenterol. 2018;24(17):1825-38. 
15. Ha NB, Trinh HN, Rosenblatt L, Nghiem D, Nguyen $\mathrm{MH}$. Treatment outcomes with first-line therapies with entecavir and tenofovir in treatment-naive chronic hepatitis B patients in a routine clinical practice. J Clin Gastroenterol. 2016;50(2):169-74.

16. Chotiyaputta W, Hongthanakorn C, Oberhelman K, Fontana RJ, Licari T, Lok ASF. Adherence to nucleos(t)ide analogues for chronic hepatitis B in clinical practice and correlation with virological breakthroughs. J Viral Hepat. 2012;19(3):205-12.

17. Sogni P, Carrieri MP, Fontaine $H$, et al. The role of adherence in virological suppression in patients receiving anti-HBV analogues. Antivir Ther. 2012;17(2):395-400.

18. Backus LI, Belperio PS, Loomis TP, Han SH, Mole LA. Screening for and prevalence of hepatitis B virus infection among high-risk veterans under the care of the US Department of Veterans Affairs: a case report. Ann Intern Med. 2014;161:926-928.

19. Serper M, Choi G, Forde KA, Kaplan DE. Care delivery and outcomes among US veterans with hepatitis B: a national cohort study. Hepatology. 2016;63:1774-82.

20. Hunt CM, Beste LA, Lowy E, et al. Veterans health administration hepatitis B testing and treatment with anti-CD20 antibody administration. World J Gastroenterol. 2016;22(19):4732-40. https://doi. org/10.3748/wjg.v22.i19.4732.

21. Veterans Health Administration. Washington DC: US Department of Veterans Affairs; c1930-2017; About VHA. Updated July 14, 2019. 2019. https:// www.va.gov/health/aboutVHA.asp. Accessed $29 \mathrm{Jul}$ 2018.

22. Charlson M, Szatrowski TP, Peterson J, Gold J. Validation of a combined comorbidity index. J Clin Epidemiol. 1994;47(11):1245-51.

23. Sterling RK, Lissen E, Clumeck N, et al. Development of a simple noninvasive index to predict significant fibrosis in patients with $\mathrm{HIV} / \mathrm{HCV}$ coinfection. Hepatology. 2006;43(6):1317-25.

24. Lachenbruch PA. Comparisons of two-part models with competitors. Stat Med. 2001;20(8):1215-34.

25. Moorman AC, Gordon SC, Rupp LB, et al. Baseline characteristics and mortality among people in care for chronic viral hepatitis: the chronic hepatitis cohort study. Clin Infect Dis. 2012;56(1):40-50.

26. Juday $T$, Tang $H$, Harris M, Powers AZ, Kim E, Hanna GJ. Adherence to chronic hepatitis B treatment guideline recommendations for laboratory monitoring of patients who are not receiving antiviral treatment. J Gen Intern Med. 2011;26(3): 239-44.

27. Beutels P. Economic evaluations of hepatitis B immunization: a global review of recent studies (1994-2000). Health Econ. 2001;10(8):751-74.

28. Brooks EA, Lacey LF, Payne SL, Miller DW. Economic evaluation of lamivudine compared with interferon-alpha in the treatment of chronic hepatitis B in the United States. Am J Manag Care. 2001;7(7):677-82.

29. Yuan Y, Iloeje UH, Hay J, Saab S. Evaluation of the cost-effectiveness of entecavir versus lamivudine in hepatitis BeAg-positive chronic hepatitis B patients. J Manag Care Pharm. 2008;14(1):21-33.

30. Ford N, Scourse R, Lemoine M, et al. Adherence to nucleos(t)ide analogue therapies for chronic hepatitis $B$ infection: a systematic review and metaanalysis. Hepatol Commun. 2018;2(10):1160-7.

31. Wang C, Chen V, Vu V, et al. Poor adherence and low persistency rates for hepatocellular carcinoma surveillance in patients with chronic hepatitis B. Medicine. 2016;95:35.

32. Peng J, Yin J, Cai S, Yu T, Zhong C. Factors associated with adherence to nucleos(t)ide analogs in chronic hepatitis B patients: results from a 1-year follow-up study. Patient Prefer Adherence. 2015;9: 41-5. https://doi.org/10.2147/PPA.S71510.

33. Chotiyaputta W, Peterson C, Ditah FA, Goodwin D, Lok AS. Persistence and adherence to nucleos(t)ide analogue treatment for chronic hepatitis B. J Hepatol. 2011;54(1):12-8.

34. Terrault NA, Lok AS, McMahon BJ, et al. Update on prevention, diagnosis, and treatment of chronic hepatitis B: AASLD 2018 hepatitis B guidance. Hepatology. 2018;67(4):1560-99.

35. Jackevicius CA, Mamdani M, Tu JV. Adherence with statin therapy in elderly patients with and without acute coronary syndromes. JAMA. 2002;288:462-7.

36. Cramer J, Rosenheck R, Kirk G, et al. Medication compliance feedback and monitoring in a clinical trial: predictors and outcomes. Value Health. 2003;6:566-73.

37. Haynes RB, McDonald HP, Garg AX. Helping patients follow prescribed treatment: clinical applications. JAMA. 2002;288:2880-3.

38. Osterberg L, Blaschke T. Adherence to medication. N Engl J Med. 2005;353:487-97.

39. Cutler RL, Fernandez-Llimos F, Frommer M, Benrimoj C, Garcia-Cardenas V. Economic impact of 
medication non-adherence by disease groups: a systematic review. BMJ Open. 2018;8(1):e016982.

40. Ho PM, Rumsfeld JS, Masoudi FA, et al. Effect of medication nonadherence on hospitalization and mortality among patients with diabetes mellitus. Arch Intern Med. 2006;166(17):1836-41.

41. Lieveld FI, van Vlerken LG, Siersema PD, van Erpecum KJ. Patient adherence to antiviral treatment for chronic hepatitis B and C: a systematic review. Ann Hepatol. 2013;12(3):380-91.

42. Sarpel D, Baichoo E, Dieterich DT. Chronic hepatitis $\mathrm{B}$ and $\mathrm{C}$ infection in the United States: a review of current guidelines, disease burden and cost effectiveness of screening. Expert Rev Anti-infect Ther. 2016;14(5):511-21.

43. Lee TA, Veenstra DL, Iloeje UH, Sullivan SD. Cost of chronic hepatitis B infection in the United States. J Clin Gastroenterol. 2004;38(10 suppl 3):S144-7.

44. Kim WR. Emerging therapies toward a functional cure for hepatitis B virus infection. Gastroenterol Hepatol (N Y). 2018;14(7):439-42.

45. Hepb.org. Hepatitis B Foundation: Drug Watch. 2019. http://www.hepb.org/treatment-and-manage ment/drug-watch/. Accessed 1 May 2019. 